\title{
TRANSFORMACIJA OBRAMBNEGA RESORJA - RAZUMEVANJE V SVETU IN PRI NAS
}

\author{
DEFENCE SECTOR TRANSFORMATION: \\ AS UNDERSTOOD IN THE WORLD AND SLOVENIA
}

Povzetek Definicije transformacije v svetu in pri nas so številne in različne, še bolj pa so različna dojemanja globine transformacijskih sprememb in poti, potrebnih za njeno uresničevanje. Transformacija ni preprosta manjša sprememba organizacije, pač pa organizirano prilagajanje organizacije za njeno uspešno delovanje v prihodnje. Za njeno izvajanje uspešne organizacije razvijajo in angažirajo svoje najdragocenejše potenciale. Članek obravnava vprašanja opredelitve transformacije in vzvode uresničevanja transformacijskih sprememb.

Ključne

Transformacija, obramba, inovacije, vodenje, gibka organizacija.

besede

Abstract The term transformation has various definitions that are used in the world and Slovenia. What is more, the comprehension of the depth needed to undertake the transformation and of the ways to implement it is even more complex. The transformation is not a simple and minor change within an organization. It is an organized adaptation of an organization aimed to ensure its successful performance in the future. For the transformation to be successful, organizations develop and engage their most valuable assets. The article discusses issues concerning the definition of the transformation and aspects of implementing the transformation.

Key words Transformation, defence, innovation, leadership, agile organisation. 
Uvod Spremenjene varnostne in ekonomske razmere ter napredek v tehnološkem razvoju so prevladujoči vzroki, ki so večino evropskih držav pripeljali do odločitev za spreminjanje svojih oboroženih sil. Poglavitni cilj sprememb je vzpostavljanje ravnovesja med grožnjami, doktrino delovanja in ekonomskimi razmerami, ki se nenehno spreminjajo. Nenehno spreminjanje zahteva tudi nenehno prilagajanje.

Obseg in predvsem globina sprememb in s tem učinki so odvisni od številnih dejavnikov, katerih razumevanje je pomembno za spodbujanje transformacijske kulture organizacije ter uspešno uveljavitev sprememb. Organizacije se transformacije lotevajo zelo različno, $\mathrm{z}$ različnimi pričakovanji in metodami, vse pa z jasnim razumevanjem nujnosti sprememb. Pogosto avtorji navajajo težavnost sprememb in vzroke za to, ki so še posebno izraziti pri radikalnejših transformacijskih spremembah. Nujnost sprememb na eni strani in tveganja na drugi zahtevajo celovit pristop, ki upošteva številne dejavnike sprememb. Različni pristopi k transformaciji obrambnih resorjev ali nacionalnih vojsk izhajajo iz različnih pojmovanj transformacije, ciljev in pogledov na nadaljnji razvoj.

V tem članku analiziramo opredelitve, globino transformacije in temeljne elemente uresničevanja transformacijskih ciljev po svetu in pri nas. Dosedanji potek transformacije na Ministrstvu za obrambo Republike Slovenije je prinesel prve rezultate in tudi prva spoznanja o zahtevnosti take naloge. Analiza teoretičnih in praktičnih spoznanj transformacije v obrambnih resorjih in podjetjih zahodnih držav so podlaga za primerjalno analizo nacionalnih pogledov na transformacijo ter končne ugotovitve.

\section{TEORIJA IN PRAKSA TRANSFORMACIJE}

Definicije transformacije se v splošnem razlikujejo med seboj glede obsega in globine v posameznih primerih, tako v svetu kot pri nas. Najpogosteje je že iz definicije mogoče razumeti opredelitev predmeta in obsega transformacije.

\subsection{Splošno pojmovanje transformacije}

Slovar slovenskega knjižnega jezika pojasnjuje transformacijo kot preoblikovanje ali preobrazbo in kot spremembo ali pretvorbo. Prvi pomen je bolj oblikovne narave, kot na primer umetniška transformacija resničnosti, drugi pomen pa je bolj vsebinski, kot na primer pretvorba vodne energije v električno (SAZU, 2008).

Pred vsako spremembo in odobritvijo investicij v transformacijo se mora vodstvo v prvi fazi odločiti o obsegu in značaju spremembe. Spremembo lahko uvrstimo glede na obseg spremembe v modelu delovanja in mobilizacijo udeleženih (slika 1). Obseg predstavlja celotno spremembo v zmogljivostih, potrebnih za spremembo modela operativnega delovanja (na primer sprememba v konceptu delovanja, procesih, tehnologiji, organizaciji, organizacijskem vedenju in kulturi). Mobilizacija se nanaša na obseg vključenih ljudi, na primer na število ljudi, organizacijskih enot in lokacij 
(Roussel, 2005). Včasih so spremembe lahko tudi postopne, saj zmogljivosti že obstajajo in so potrebni le popravki v zmanjševanju stroškov, kakovosti ali krajših časih realizacije nalog. Sprememba glavnih zmogljivosti in koncepta operativnega delovanja ali široka mobilizacija pa spremembo določa kot transformacijsko, na primer nov model poslovanja ali nove zmogljivosti, zmanjševanje stroškov režije, bistvene spremembe v kakovosti izdelkov in storitev v celotni organizaciji. Jasnost odločitev o globini spremembe je zelo pomembna za pridobitev ustrezne podpore udeleženih in izvajanje procesa spremembe.
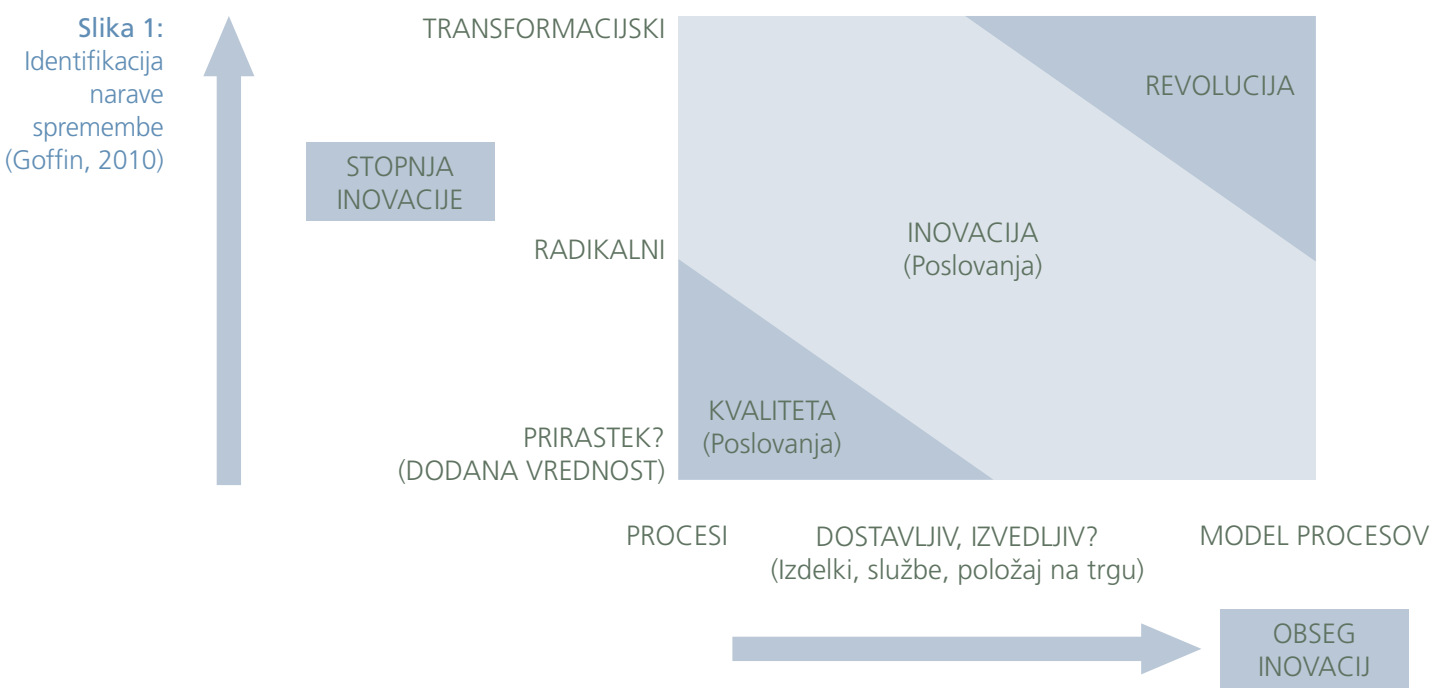

Obvladovanje sprememb je proces za pridobivanje podpore pri vseh, ki se jih spremembe dotikajo. Roussel (2008) izpostavlja transformacijske programe, ki so bolj celoviti in zajemajo več ljudi. Izvedba transformacijskih programov zahteva dodelitev virov in določitev prednosti. Vodilne organizacije vzpostavijo izvajanje transformacije in redno operativno delo vzporedno. Po ugotovitvah Roussla transformacijski programi zahtevajo znatno krajši čas implementacije sprememb za isti učinek kot pa klasični programi sprememb.

\subsection{Pojmovanje vojaške transformacije}

Pojem transformacije je nadomestilo za besedo sprememba, ki pa različnim narodom, organizacijam in posameznikom pomeni različno. Hammond (2009) omenja obstoj najmanj treh različic razumevanja besede transformirati. Prva je v spremembi zunanje podobe, kot je pridobitev nove opreme. Druga je sprememba stanja, narave ali funkcioniranja in pomeni pretvorbo v nekaj drugega. Tretja je sprememba osebnosti ali karakterja, ki je bistveno bolj celovit proces, nujen za spoprijemanje z izzivi 21 . stoletja. Številne vojske se osredotočajo na prvi pomen pojma transformacije, ki 
pomeni modernizacijo in postavlja težišče na tehnični vidik sprememb. Številne so pristopile k racionalizaciji, celo bistvenemu zmanjšanju vojske ter pretvorbi v manjše in zmogljivejše sile s spremembo organizacije, procesov in doktrine transformiranih sil. Hammond (2009) trdi, da je bistvo uspešne transformacije temeljita sprememba zmožnosti drugačnega razmišljanja, izobraževanja in urjenja, potrebnega za sposobnost prilagajanja na prihodnje izzive.

Pojem vojaške transformacije je zadnji od medsebojno povezanih pojmovanj, ki so se pojavila $\mathrm{v}$ zadnjih desetletjih, in opisujejo spremembe, ki se dogajajo $\mathrm{v}$ vojskah zahodnih držav. Pogledi na transformacijo so bili neposredno ali posredno povezani z razumevanjem vpliva tehnologije na vojskovanje in nujnost povezovanja tehnoloških, doktrinarnih in organizacijskih sprememb, da bi pomagali vojskam pri prilagajanju spremenjenim varnostnim izzivom moderne dobe (Sloan, 2007).

Alberts (2005) opredeljuje večdimenzionalnost transformacije ameriškega obrambnega ministrstva, ki obsega spremembe narave vojaških nalog, spremembe v načrtovanju in izvajanju vojaških operacij ter spremembe poslovnih procesov, ki ustvarjajo zmogljivosti, potrebne za izvajanje operacij. Ti procesi obsegajo tudi neposredno in posredno podporo izvajanju operacij. Cebrowski (2003) vidi transformacijo kot sočasni razvoj konceptov, procesov, organizacije in tehnologije. Sprememba na vsakem izmed teh področij zahteva spremembo v preostalih. Za zaključevanje vojaške naloge je potreben niz medsebojno povezanih zmogljivosti, ki jih lahko razumemo kot paket zmogljivosti za izvajanje vojaške naloge. Alberts (2005) jih opisuje kot paket zmogljivosti (angl. Mission capability package), ki so v medsebojni odvisnosti. Za zmogljivosti poslovnih procesov so značilni kadri, model procesov in informacijska tehnologija. Vojaške zmogljivosti pa najpogosteje opisujejo še z dodatnimi elementi, kot so koncepti bojevanja in doktrine, usposobljenost, voditeljstvo in interoperabilnost. Zmogljivost je celovita, če je doseženo skladje vseh elementov.

Transformacijo razumemo kot proces, ki spreminja stanje oboroženih sil z uporabo novih konceptov, novih zmogljivosti, kadrovskih potencialov z novimi znanji in novo organizacijsko strukturo (Gehman, 2004). V zamisel o transformaciji vojske sta vgrajeni dve bistveni lastnosti, in sicer ideja o spremembi in ideja o vzroku ter posledici (Labbe, 2005). Transformacijo na obrambnem področju je O'Rourke (2006) opredelil kot skokovito spremembo velikega obsega, po možnosti prebojno, V vojaški oborožitvi, konceptih delovanja in organizaciji. Vse prepogosto pa smo, kadar govorimo o transformaciji obrambnega resorja, priča poenostavitvam, $\mathrm{v}$ katerih je transformacija sinonim za zmanjševanje obsega in proračuna obrambe. V realnosti je transformacija obrambnega področja večplastna in s številnimi ostmi, pri čemer je bistveno sodelovanje vladnih organov, obrambne industrije in civilne družbe. V RS ta proces poteka skozi oblikovanje dolgoročne rešitve, srednjeročnega obrambnega programa in na proračunskih usklajevanjih, ko se določa dvoletni izvedbeni poslovni plan obrambnega resorja. 
Paketi vojaških zmogljivosti prihodnosti predstavljajo pravo vrednost transformacije, ki pa se razlikujejo po stopnji inovacij, vključenih v celovit paket vojaške zmogljivosti (Alberts, 2005). Inoviranje, uvedba nečesa novega ali neobičajnega, je osrčje transformacije, ki pa se ne konča z odkritjem ali stvaritvijo, temveč z uveljavitvijo v praksi. Sposobnost za oblikovanje novih idej in njihovo uresničevanje v praksi je zelo pomembna sposobnost danes in bo še bolj pomembna $\mathrm{v}$ prihodnosti.

Transformacijo vojske ZDA je začelo njihovo ministrstvo za obrambo, da bi ohranilo vojaške prednosti. Razloge za transformacijo lahko strnemo v tri točke:

- spoznanje, da je nacionalno in globalno varnostno okolje 21. stoletja popolnoma drugačno od ustaljenih pogledov ter zahteva drugačne zmogljivosti in kompetence;

- informacijska doba in nove tehnologije ponujajo nepredvidene možnosti za razvoj operativnih konceptov, ki lahko občutno povečajo konkurenčne prednosti;

- poslovne procese v obrambnih strukturah je treba prilagoditi tako, da zagotavljajo hitro prilagajanje spremembam na polju globalne in nacionalne varnosti.

VNaturazumemo transformacijo kot proaktiven proces razvoja in uvajanja inovativnih konceptov, doktrine in zmožnosti, da bi se izboljšali uspešnost in interoperabilnost Nata in partnerjev (vir: MC 0583, MC Policy for Nato Concept Development and Experimentation). Umešča se v Natov proces obrambnega planiranja, pri katerem zavezništvo išče najboljše rešitve za primanjkljaje v zmogljivostih. V svetu sprememb številne oborožene sile in zveza Nato iščejo rešitve v prilagajanju zmogljivosti za delovanje ter ustrezen odziv na grožnje varnosti današnjega časa, spremenjene ekonomske pogoje in nepredvidljive okoliščine uporabe sil. Evropski obrambni sistemi svojo transformacijo navadno udejanjajo s spremembami na področju razvoja zmogljivosti, doktrine poveljevanja in kontrole ter razvoja za delovanje v mrežnemu okolju (Teriff, 2010). Pogosta je doktrinarna usmerjenost za delovanje zunaj nacionalnega prostora, ki se navadno izvaja v sodelovanju s koalicijskimi partnerji. Za tako delovanje je potrebna transformacija nacionalnih zmogljivosti k skupnim standardom, vključno s tehnološkimi, saj je brez učinkovite izmenjave informacij sodelovanje zelo oteženo (Smith, 2006).

Resolucija o dolgoročnem programu razvoja in opremljanja Slovenske vojske (v nadaljevanju: SV) do leta 2025 (ReSDPRO SV 2025) opredeljuje potrebo po transformaciji SV in preoblikovanju ter racionalizacijo upravnega dela MO. Od zagotovitve pogojev in sposobnosti za pravočasno transformacijo z vidika obsega in strukture, organiziranosti ter opremljenosti in usposobljenosti Slovenske vojske bo v veliki meri odvisna sposobnost uspešnega in učinkovitega odzivanja Slovenske vojske na vojaške grožnje in njeno sodelovanje (ReSDPRO). Splošno uveljavljen namen transformacijskih aktivnosti, proučevanje obrambnih zmogljivosti in njihovo ustrezno prilagajanje prihodnjim zahtevam so uveljavljeni tudi v slovenskem obrambnem resorju. Srednjeročni obrambni program (SOPR) do leta 2018 predvideva prednostne transformacijske spremembe na področju preoblikovanja SV, integracije strateške ravni in spremembe pri kadrih, v logistiki ter komunikacijskih in informacijskih sistemih. Temelji naj na nenasilnem, domišljenem pristopu, znanju 
in prednostih informacijske družbe ter spreminjanju obrambno-vojaških struktur, organiziranosti in nalog ter vloge vojske v družbi (Šteiner, 2009, str. 119-123). Tak pristop pa zahteva vzpostavitev ustreznih vzvodov, prek katerih se cilji transformacije posledično uresničujejo.

\subsection{Vzvodi transformacije}

Spremembe so potrebne zaradi nenehnih sprememb v družbi, vendar podrobnosti izvedbe pogosto ostajajo potovanje v neznano. Splošen dogovor o okvirni spremembi je lahko doseči, podrobnosti o novem pristopu v poveljevanju in kontroli, doktrini, izobraževanju in usposabljanju pa je najpogosteje treba še oblikovati. Razvoj in vzpostavitev vojaških zmogljivosti prihodnosti se v praksi razlikujeta od razvoja zmogljivosti za izvajanje poslovnih procesov po številu elementov zmogljivosti ter načinu njihovega oblikovanja. Razvoj vojaških zmogljivosti je podvržen disciplini obrambnega načrtovanja in programiranja. Za njihovo uveljavitev v praksi pa so potrebni številni dodatni vzvodi.

Po sprejemu odločitve o obsegu in globini transformacijskih sprememb je od vzvodov za izvajanje transformacijskih aktivnosti odvisno njihovo uresničevanje. Vzvodi sprememb so mehanizmi, prek katerih organizacija uresničuje spremembe v sposobnosti za bistveno spremenjeno izvajanje poslanstva. Med številnimi vzvodi podrobneje obravnavamo obvladovanje procesov in razvoj potencialov, kot so razvoj kadrovskih sposobnosti, razvoj strateških tehnologij ter pripravljenost za razvoj in akcijo.

\subsubsection{Procesi}

$\mathrm{Na}$ rezultate organizacije neposredno vpliva stopnja zrelosti procesov. Proces je v splošnem niz aktivnosti, ki jih izvajajo akterji procesov z ustreznimi orodji in potrebnimi viri informacij za izvedbo izdelka ali storitve. Transformacijski proces je del procesov, s katerimi se organizacija prilagaja prihodnjim zahtevam.

Obvladovanje procesov in stopnja avtomatizacije poslovanja omogočata prehod na nove oblike organiziranosti, kot je matrična ali procesna, kar ima za posledico hitrejše odzivanje na spremembe v okolju in učinkovitejše upravljanje. V obrambnih resorjih so procesi večplastni in težje razumljivi, saj se še vedno pogosto ohranjajo funkcije kot prevladujoča oblika organiziranja. Izkušnje komercialnih organizacij pri razvoju novih izdelkov in storitev ter stalnem prilagajanju spremembam na trgu prodirajo tudi v obrambne resorje, kjer take izkušnje ustvarjalno uporabljajo za reševanje specifičnih izzivov razvoja vojaških zmogljivosti. Najhitreje se prenos izkušenj uresničuje na manj vojaško specifičnih področjih, kot je logistika, informacijska tehnologija ali razvoj kadrov.

Za razvoj novih storitev, izdelkov ali zmogljivosti je zelo pomembna inovacijska sposobnost organizacije. Inovacijski proces (slika 2) zahteva vodenje, ki spodbuja nastajanje idej, njihovo selekcijo in usmerjanje h konceptualnim odločitvam ter oblikovanju izvedbenih razvojnih ali transformacijskih projektov. 


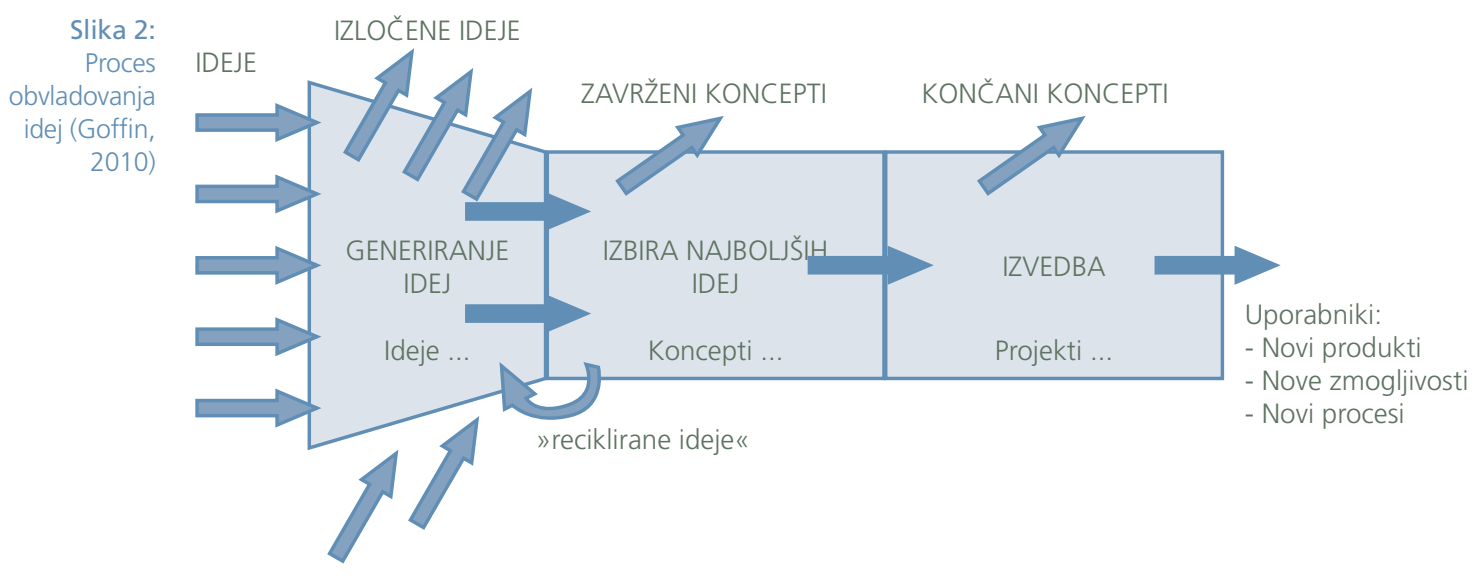

IDEJE IZ ODPRTIH INOVACIJ

Razvoj konceptov in eksperimentiranje (CD\&E) je v Natu uveljavljen proces (CD\&E je angleška kratica za Concept Development and Experimentation) za inovativno uresničevanje transformacijskih sprememb. Metodologija CD\&E obsega pripravo osnovnega koncepta in njegov nadaljnji razvoj, verifikacijo in odločanje ob izvedbi niza eksperimentov. Metodologija omogoča nastanek inovativnih, izvedljivih in učinkovitih rešitev za ugotovljene pomanjkljivosti $\mathrm{v}$ okviru načrtovanih rokov in danih virov. Eksperimentiranje je metoda za pridobivanje novega razumevanja groženj in novih vidikov uporabe alternativnih rešitev (NATO SACT, 2005). Ob pomanjkanju virov in pritisku rokov je treba prepoznati in obvladovati tveganja sprememb. Tveganja so prehitro napredovanje zamisli v izvedbo brez zadostnih dokazov in razumevanja vzročno-posledičnih zvez, prezgodnja pomiritev le z eno potjo reševanja, napredovanje na podlagi poskusov in napak namesto sledenju teoretičnim dokazom, nizka stopnja uporabe potenciala lastnih kadrov in druga (Alberts, 2005). Številna tveganja kažejo na nujnost kakovostnega procesa transformacije. $Z$ eksperimenti se ob uporabi znanstvenih metod in analiz iščejo ter preverjajo rešitve za zapolnitev vrzeli med trenutnim in ciljnim stanjem zmogljivosti.

Odmeven primer transformacije procesov v Natu je koncept podpore logističnih rešitev za mednarodne operacije, da bi se zagotovila višja učinkovitost. V tem primeru je Nato oblikoval model procesa za logistično obvladovanje razvoja sil in podpore mednarodnih operacij (angl. Business Process Model for NATO Operations Logistic Chain Management (OLCM) for Deployment and Sustainment). Model opisuje celovito preoblikovanje logističnih procesov z upoštevanjem najnovejših konceptov logistike in zmogljivosti informacijske tehnologije. Model procesov je bil verificiran $\mathrm{z}$ metodologijo preigravanja razvojnih konceptov (angl.: Concept Development Assessment Game (CDAG)). Na podlagi ugotovitev eksperimenta je bil izboljšan in uporabljen na vaji, na kateri je bil dodatno preverjen z vidika učinkovitosti in praktičnosti pred odločitvami o uveljavitvi v praksi. To je primer odlično prenesenih metod iz poslovnega sveta na področje obrambe, na katerem je 
bil proces razvoja konceptov in eksperimentiranja zastavljen tako, da je sistematično pripeljal idejo o spremembi do njene zrelosti za odločitev o uvedbi.

Temelj sposobnosti organizacije za ustrezno prilagajanje izzivom prihodnosti je $\mathrm{v}$ izvajanju transformacijskega procesa, ki pa ga ne smemo jemati samo z vidika njegovih formalnih faz. Začne se že pri viziji spremembe, ki je stvar vodenja in podlaga za uspešno oblikovanje spremembe ter njeno uresničitev. Za spremembo je potrebno delovanje kadrovskega potenciala organizacije, ki lahko z inovacijami doseže bistvene spremembe in zamisli tudi uresniči.

\subsubsection{Razvoj potencialov}

Interni procesi in učinki delovanja organizacije značilno razkrivajo velike vrzeli med trenutnimi sposobnostmi ljudi, sistemov in postopkov ter tistimi, ki so potrebne za uresničevanje izboljšanega delovanja organizacije (Alberts, 2005). Za zapolnitev te vrzeli mora organizacija investirati v spremembo kompetenc ljudi, izboljšati dostop do informacij, informacijske tehnologije in sisteme ter uskladiti organizacijske postopke in cilje zaposlenih s cilji organizacije (Kaplan, 1996). Vidik učenja in rasti je temelj vsake strategije sprememb (Kaplan \& Norton, 2001, str. 93).

Potenciali za učenje in rast so kompetence, ki postavljajo temelje za razvoj klasičnih vzvodov sprememb, kot so zadovoljstvo zaposlenih, motiviranost in produktivnost. Vpliv na osebnostni razvoj kadra in organizacijsko vedenje se neposredno kaže $\mathrm{v}$ razvoju kadrovskih kompetenc, razvoju in uporabi strateških tehnologij, dostopu do informacij in razvoju organizacijske klime (Laske, 2001). Strategija sprememb je zelo odvisna od organizacijskih vrednot, ki pa jih je za spremenjene cilje treba spremeniti, saj spremenjene vrednote vplivajo na organizacijsko vedenje, ki se kaže na drugih pokazateljih sprememb. Tudi razvoj inovacijske kulture v organizaciji zahteva skrbno načrtovane ukrepe, ki se nanašajo na najbolj subtilne dejavnike, ki vplivajo na človeško vedenje v organizaciji (Buytendijk, 2009). Razvoj inovativnosti je dejavnik, ki ga številne organizacije definirajo preozko in pri tem stavijo na ozek tim ljudi in produkte, ki jih ti razvijajo. V primerjavi s tem uspešni inovacijski vodje opredeljujejo inovativnost širše in v izboljšave storitev, procesov, poslovnih modelov, komuniciranja ali strukture stroškov vključujejo celotno organizacijo (Adachi, 2012).

Vodenje so skupinske aktivnosti članov organizacije, s katerimi se postavljajo usmeritve, gradi prevzemanje obveznosti in ustvarja usklajenost (McCauley in Van Velsor, 2004). Ta opredelitev obsega aktivnosti ali sposobnosti vodilnih v organizaciji za oblikovanje jasne vizije in delitev te vizije z drugimi tako, da so ji pripravljeni slediti. Vključuje tudi zagotavljanje informacij, znanja in metod za uresničitev vizije in usklajevanje konfliktnih interesov vodilnih in deležnikov (Poslovni slovar). Vodenje ni proces menedžmenta, temveč mehkejši socialni vpliv, ki maksimira prizadevanja drugih za uresničitev ciljev (Kruse, 2013). Martin in Ernst (2005) ugotavljata, da večplastne spremembe zahtevajo nova znanja, vire in poglede, ki jih je mogoče najti zunaj organizacije. Ti izzivi zahtevajo tudi spremembo v voditeljstvu, ki se od klasičnega individualnega vodje giblje v smer bolj inovativnih vodij in 
sodelovanja. Šavc in Mikuž (2009) ugotavljata, da je uveljavljanje nacionalnih ciljev sil, dogovorjenih z Natom, v Sloveniji prispevalo predvsem k uporabnejšim in racionalnejšim vojaškim zmogljivostim. Tako sta Slovenija in zavezništvo dobila potrditev, da je mogoče doseči cilje s konsistentno obrambno politiko in načrtovanjem ter usklajenostjo ciljev na vseh ravneh. O nujnosti usklajenosti ciljev in meril po celotni organizacijski strukturi govori tudi Kaplan (2001), ki meni, da je le tako mogoče usmeriti energijo in vire organizacije v skupne in pomembne cilje.

Nič se v organizaciji ne zgodi brez človeškega dejavnika. Šteiner (2011, str. 57) predlaga, da se čim prej uvede nov kompetenčni model za vojaške profesionalce, saj slovenski obrambni sistem in Slovenska vojska v obdobju tranzicije nista dokončno odpravila starega modela, ki ni primerljiv s tistim, ki ga imajo skoraj vse preostale članice zavezništva. Brez najpomembnejših strateških sistemov si napredka organizacije danes ni mogoče več predstavljati. V strateške sisteme poleg oborožitvenih sistemov uvrščamo tudi informacijsko tehnologijo. Brez vizionarskega vodenja in podpore je večina sprememb informacijske tehnologije neučinkovitih, saj je zelo malo verjetnosti, da bo samo z vidika uvajanja informacijske tehnologije dosežena ustrezna mobilizacija za podporo preoblikovanja procesov in transformacije organizacije (Attaran, 2004). Posledično preoblikovanja procesov ni mogoče uveljaviti brez zagotovitve dostopa do kakovostnih informacij za odločanje na vseh ravneh organizacije (Popovič in soavtorji, 2009).

S sprejetjem SOPR 2013-2018 si je Ministrstvo za obrambo RS postavilo razvojne cilje, ki vključujejo tudi potenciale rasti. Med njimi izstopajo uveljavitev kompetenčnega modela, uvajanje merjenja uspešnosti in učinkovitosti, razvoj organizacijske kulture in izboljšanje dostopa do najpomembnejših informacij.

\section{RAZISKAVA POGLEDOV NA TRANSFORMACIJO}

$\mathrm{Na}$ podlagi analize strokovne literature o transformaciji je mogoče sklepati o skupnih pogledih na opredelitev transformacije, o procesu izvajanja in o dejavnikih njenega uspešnega uresničevanja. Cilj raziskave je bil ugotoviti, kje transformacija obrambnega resorja sledi splošnim opredelitvam in kje se potencialno razlikuje.

Na podlagi pogledov iz strokovne literature je bil oblikovan vprašalnik. Z odgovori so anketirani izrazili poglede, ki so si jih o vprašanjih transformacije oblikovali do septembra 2013. Vprašalnik je vseboval 14 vprašanj, ki so se nanašala na opredelitev transformacije, globino, proces in vzvode transformacije. Vprašalnik je podpiral preverjanje teze, da pogledi zaposlenih o transformaciji $\mathrm{v}$ obrambnem resorju $\mathrm{v}$ povprečju ne odstopajo od ugotovitev iz strokovne literature.

Na vprašanja je v obdobju enega meseca izmed 250 naključno izbranih zaposlenih na anketo odgovorilo 60 zaposlenih. Med anketiranimi je bilo 28,3 odstotka vodilnih delavcev MO in SV. Na ravni 5-odstotne verjetnosti ni statistično pomembnih razlik $\mathrm{v}$ odgovorih med vodilnimi in drugimi zaposlenimi. 
$\mathrm{Na}$ vprašanje o razumevanju opredelitve pojma transformacije je bilo izraženo večinsko mnenje anketiranih ( 83 odstotkov), da je transformacija proces, ki spreminja stanje vojske $\mathrm{z}$ uporabo novih konceptov, novih zmogljivosti, kadrovskih potencialov z novimi znanji in novo organizacijsko strukturo (slika 3). Sledijo jim anketirani (10 odstotkov), ki transformacijo razumejo kot hkratni razvoj konceptov delovanja, procesov, organizacije in tehnologije, in tisti, ki menijo, da transformacija pomeni spremembe poslovnih procesov (7 odstotkov). Za ponujeni pojem transformacije kot spremembe narave vojaških nalog ali spremembe $\mathrm{v}$ načrtovanju in izvajanju vojaških nalog se ni opredelil nihče izmed anketiranih.

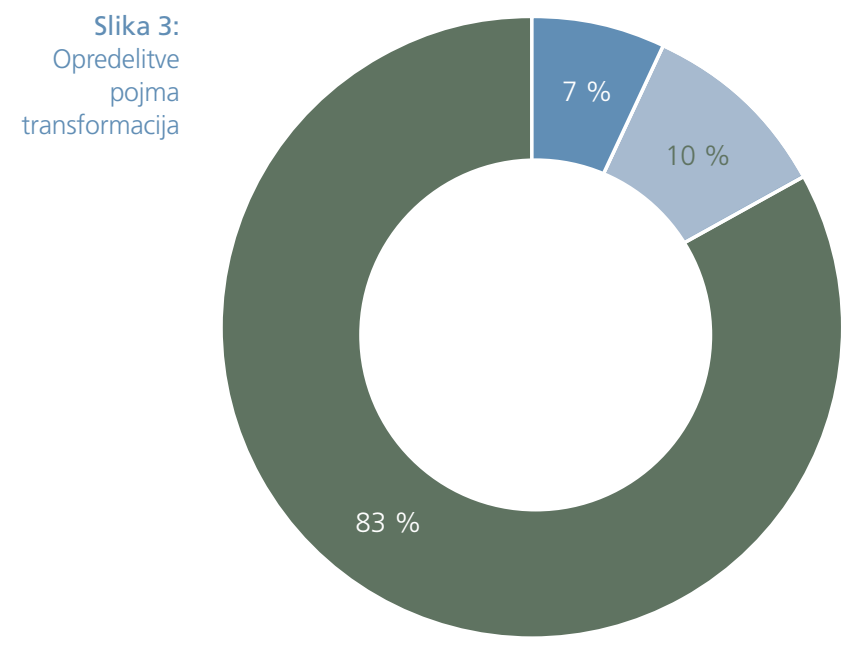

Spremembe poslovnih procesov, ki ustvarjajo zmogljivosti, potrebne za izvajanje operacij

Sočasni razvoj konceptov delovanja, procesov, organizacije in tehnologije

- Proces spreminjanja stanja oboroženih sil z uporabo novih konceptov, novih zmogljivosti, kadrovskih potencialov in novo organizacijsko strukturo

Na vprašanje o globini sprememb na MO, ki jo lahko ocenimo z obsegom vsebinske spremembe in števila ljudi, vključenih $\mathrm{v}$ spremembe, so mnenja deljena in enakomerno razporejena. Pri tem 28 odstotkov anketiranih meni, da gre za manjše spremembe, 36 odstotkov anketiranih pa meni, da gre za spremembe bistvenih elementov zmogljivosti ali bistveno spremembo miselnosti in konceptov delovanja za prihodnost.

Poznavanje transformacijskega procesa, ki ga opredeljuje metodologija razvoja konceptov in eksperimentiranja, je slabo, s povprečno oceno 2,05. Slabo je tudi poznavanje procesa razvoja zmogljivosti (povprečna ocena 2,60). Obe oceni ne odstopata bistveno od ocene razvojne stopnje obvladovanja poslovnih procesov na obrambnem področju, ki je po oceni s povprečno oceno 2,07 na drugi razvojni stopnji zrelostnega modela. Po metodologiji ocenjevanja zrelosti druga stopnja pomeni, da je del procesov organiziranih in se obvladovanje izvaja na ravni oddelkov. 
$\mathrm{Na}$ vprašanje o organizaciji za transformacijo obrambnega resorja prevladuje večinsko mnenje (65 odstotkov anketiranih), da je najbolj primerna organizacijska rešitev posebna organizacijska enota (delovna skupina za transformacijo-DST), ki tesno sodeluje z notranjimi organizacijskimi enotami. Sledi rešitev, v kateri notranje organizacijske enote izvajajo proces transformacije po redni poti (20 odstotkov). Anketirani so najmanj naklonjeni rešitvi, pri kateri neodvisna organizacijska enota pripravlja predloge transformacijskih sprememb (15 odstotkov).

Slika 4:

Primernost organizacijske rešitve

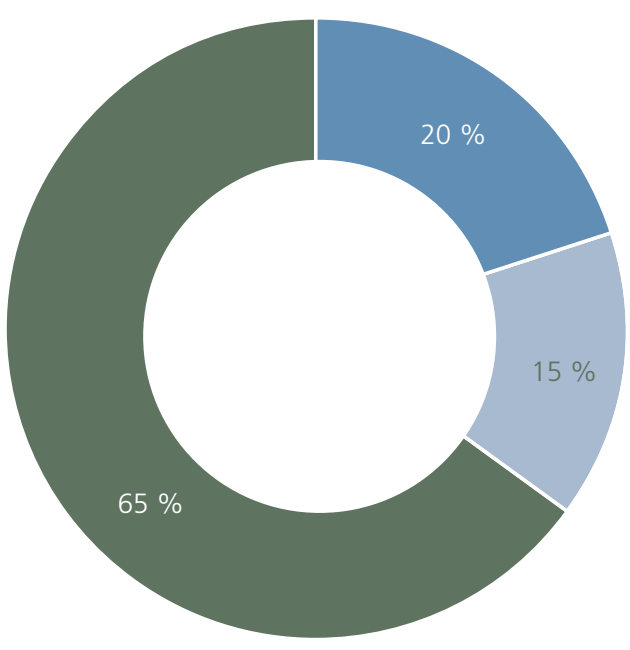

Delo NOE

Neodvisna OE

Vzporedno delo DST in NOE

Slika 5: Povprečne ocene pomembnosti vzvodov sprememb

Primernost

\begin{tabular}{r|r|r|}
\hline $\begin{array}{r}\text { Sprememba inovativne } \\
\text { organizacijske strukture }\end{array}$ & \multicolumn{2}{|l|}{} \\
Investicije v nove & & \\
informacijske rešitve & Nabava novih \\
oborožitvenih sistemov & & \\
\hline $\begin{array}{r}\text { Spremembe in uveljavljanje } \\
\text { normativne ureditve }\end{array}$ & & \\
\hline Sprememba razvojnih potencialov & & \\
\hline Sprememba internih procesov & & \\
\hline Preoblikovanje & & \\
\hline organizacijske strukture & 3 & 4
\end{tabular}


Glede vzvodov, ki naj jih MO uporablja v procesu transformacije, so anketirani z oceno na lestvici od 1 do 5 največji pomen (povprečna ocena 4,52) pripisali razvojnim potencialom, kot so kompetence kadrov, razvoj strateških tehnologij, dostop do informacij ter pripravljenost na spremembe in akcijo. Sledita jim razvoj inovativne organizacijske kulture (povprečna ocena 4,45) in sprememba internih procesov s povprečno oceno 4,19. Za uspeh procesa transformacije se jim zdijo manj pomembni nabava opreme $(3,29)$, investicije v informacijsko tehnologijo $(3,69)$ in spreminjanje normativne ureditve $(3,93)$.

V razlagah in predlogih sprememb anketirani pogosto omenjajo potrebo po sistemskih spremembah, ki bodo od birokratskega odnosa pripeljali do profesionalnega odnosa današnjega časa. Pogosto anketirani predlagajo bolj korenite spremembe $\mathrm{v}$ kadrovski politiki, brez katerih bodo spremembe težavne, če ne že nemogoče. Samo s površinskimi spremembami, brez uveljavljanja višjih standardov, ne bo mogoče uresničiti učinkov, ki jih spremenjeno varnostno okolje zahteva in zavezništvo pričakuje.

\section{RAZPRAVA}

V preteklosti sta se upravni del MO in predvsem SV pogosto preoblikovala. Z vidika ideje o spremembi, obsega in spremembe v konceptu delovanja imajo prehodi iz Teritorialne obrambe $\mathrm{v}$ SV, od naborniške $\mathrm{v}$ profesionalno vojsko, uveljavitev standardov Nato in začetki sodelovanja v mednarodnih operacijah vse značilnosti transformacijskih sprememb. Pri celovitem obvladovanju procesa transformacije pa obrambni resor še ni izkoristil vseh možnosti, s katerimi bi lahko spremembe uresničeval še uspešneje in učinkoviteje.

V obrambnem resorju Republike Slovenije je obseg prihodnjih transformacijskih sprememb opredeljen $\mathrm{v}$ strateških in programskih dokumentih, pri čemer smeri sprememb ne odstopajo od sprememb v drugih državah. Tudi rezultati ankete kažejo visoko enotnost $\mathrm{v}$ opredelitvi pojma transformacije, ki ne odstopa od opredelitev v drugih državah. Razlike nastajajo pri določenosti globine in jasnosti vzvodov sprememb ter doslednosti uresničevanja transformacijskih ciljev. Samo opredeljevanje transformacije $\mathrm{v}$ dokumentih očitno ne zadošča. Treba je načrtovati in izvajati komuniciranje z vsemi udeleženimi, sicer ostane strategija slabo sprejeta.

O vprašanju globine transformacijskih sprememb na MO so mnenja anketiranih različna, čeprav Srednjeročni obrambni program govori o zelo pomembnih spremembah. Izvedbeni dokumenti ne opredelijo eksplicitno, katere naloge se izvajajo kot del procesa stalnih razvojnih sprememb in katere po procesu transformacije. Mnenja anketiranih je mogoče razložiti z nejasno komunikacijsko strategijo ali pa različnostjo razumevanja globine transformacije med zaposlenimi. Oba možna vzroka lahko bistveno vplivata na uspešnost izvajanja transformacijskih aktivnosti. 
Iz raziskave je mogoče ugotoviti nizko stopnjo poznavanja procesa transformacije in procesa razvoja vojaških zmogljivosti, kar dodatno lahko vpliva na uspešnost načrtovanja in uveljavljanja sprememb. Dejanska organiziranost za izvajanje transformacijskih projektov, ki potekajo $\mathrm{v}$ okviru funkcionalne organizacije z uveljavljeno hierarhično strukturo vodenja, odstopa od večinskega mnenja anketiranih, ki ocenjujejo vzpostavitev vzporedne organizacijske enote, ki bo tesno sodelovala z organizacijo, za najbolj sprejemljivo obliko organizacije. Za uspešno uresničevanje transformacije so nujne tudi spremembe v načinu organiziranja, procesu in kompetencah, ki so pomembne za kakovostno načrtovanje in uresničevanje transformacijskih sprememb.

O vzvodih, ki naj bi jih MO uporabljal v procesu transformacije, se mnenja anketiranih razlikujejo od povprečnih vzvodov v evropskih državah, ki temeljijo na racionalizaciji in spremembi organizacije, procesov in doktrine transformiranih sil. Anketirani namreč največji pomen pripisujejo razvojnim potencialom, kot so kompetence kadrov, razvoj strateških tehnologij, dostop do informacij, pripravljenost na spremembe in akcijo. Sledita jim razvoj inovativne organizacijske kulture in sprememba internih procesov. Taka mnenja so usmerjena $\mathrm{v}$ dolgoročno in trajno sposobnost prilagajanja spremembam, ki prihajajo, in ne samo v zahteve trenutnih razmer. Že stanje zrelosti internih procesov kaže, da neposreden razvoj vzvodov sprememb ni potreben samo za dolgoročne spremembe, temveč tudi za uspešno uresničevanje kratkoročnih, saj je poznavanje transformacijskega procesa, njegovih možnosti in tudi pasti bistveno za vsak transformacijski projekt. Kakovostno obvladovanje transformacijskega procesa pomeni sposobnost oblikovanja in sprejemanja jasnih in merljivih ciljev transformacijskih sprememb, ustrezno organiziranost za generiranje idej ter njihovo pretvarjanje $\mathrm{v}$ prakso delovanja, kulturo sodelovanja ter učinkovito izmenjavo in delitev informacij. Brez kakovostnega obvladovanja procesa transformacije se potencial transformacijskega projekta lahko hitro spremeni $\mathrm{v}$ proces običajnih sprememb in izničijo se prednosti transformacijskega procesa pred običajnim procesom sprememb.

\section{UGOTOVITVE IN PREDLOGI}

Transformacija je proces nenehnega prilagajanja nenehno spreminjajočim se razmeram. Pri sprejemanju odločitve o posameznem projektu sprememb mora vodstvo sprejeti tudi jasne odločitve o globini in obsegu sprememb, ki jih je mogoče uresničiti le s široko paleto ukrepov s kratkoročnimi in dolgoročnimi učinki. Ukrepi se nanašajo na spremembe v modelu operativnega delovanja, v procesih in razvoju potenciala organizacije, brez katerih ni mogoče razviti trajne sposobnosti prilagajanja.

Proces transformacije se bistveno razlikuje od procesa sprememb, kot smo ga poznali v preteklosti. Zahteva jasno vizijo o spremembah, ki so potrebne in jih po koncu transformacijskega projekta organizacija pričakuje. Jasna in usklajena strategija poti do pričakovanih učinkov, ki jo sprejmejo vsi vključeni, je temeljna 
podlaga, brez katere ni mogoče dosledno izvajati sprememb. Če organizacija vzpostavi proces izvajanja transformacijskih projektov in za spremembe angažira svoje najpomembnejše potenciale, so rezultati hitrejši, posledice sprememb bolj predvidljive in učinki sprememb bolj zanesljivo uresničljivi. Tudi bolj korenite spremembe v konceptih delovanja ne dajejo pričakovanih učinkov brez usklajene in merljive strategije, podprte $\mathrm{z}$ ustreznimi programi ukrepov in izbranimi viri. Oblikovanje strategije sprememb in njeno sprejemanje pa sta odvisna od sprememb na področjih vodenja in organizacijske kulture.

Dolgoročnih in trajnih sprememb ni mogoče uresničiti brez razvoja potencialov organizacije. Brez pravih investicij v razvoj kadra in strateških tehnologij, v izboljšanje dostopa do informacij ter pripravljenost na spremembe in akcijo bosta prilagajanje spremembam $\mathrm{v}$ okolju in uspešno uresničevanje poslanstva vedno težji. Transformacijski projekti in uporaba metodologije CD\&E pa lahko odločno prispevata $\mathrm{k}$ večji inovativnosti, razvoju in verifikaciji konceptov ter razvoju organizacijske kulture za izzive prihodnosti.

V Srednjeročnem obrambnem programu je Vlada Republike Slovenije jasno opredelila ukrepe sprememb obrambnega resorja, ki se nanašajo tako na kratkoročne kot dolgoročne ukrepe. Brez dobrega razumevanja vzročno-posledičnih odnosov, celovitega obvladovanja procesa transformacije in sistematičnega vodenja projektov transformacijskih sprememb je v zelo spremenljivem okolju ekonomske situacije nemogoče predvideti učinke ukrepov. Enkratno spreminjanje procesov na daljše obdobje ne zadošča več, organizacija mora vzpostaviti svojo sposobnost stalnega in celovitega spreminjanja. Pri tem je ob spremembi modela procesov treba doseči tesno povezanost informacijske tehnologije, virov informacij z normativno ureditvijo in razvojem kadrovskih kompetenc.

Za nenehno prilagajanje in uspešno uresničitev vsakega transformacijskega projekta in prilagajanja okolju v celoti so nujni aktivno sodelovanje vodstva, jasna strategija in njeno dosledno izvajanje v celotni organizaciji.

\section{Literatura}

1. Adachi, B., Helfrich, D., Schwartz, J., 2012. Human capital trends 2012. Deloitte Consulting LLP.

2. Alberts, D., Hayes, R., 2005. Campaigns of Experimentation: Pathways to Innovation and Transformation. Washington DC: CCRP Publication Series.

3. Attaran, M., 2004. Exploring the relationship between information technology and business process reengineering. Information \& Management. 14, str. 585-596. Bakersfield: School of Business and Public Administration, California State University.

4. Buytendijk, F., 2009. Performance leadership, The Next Practices to Motivate Your People, Align Stakeholders, and Lead Your Industry. McGraw-Hill.

5. Cebrowski, A., 2003. Military transformation, a strategic approach. Office of Force transformation, USA DoD.

6. Gehman, H., Dubik, J., 2004. Military transformation and Joint Experimentation: Two Views from Above, Defense Horizons, Number 46, National Defense University, Washington. 
7. Goffin, K., Mitchell, R., 2010. Innovation Management, Strategy and Implementation using the Pentathlon Framework. Hampshire: Palgrave Macmillan.

8. Hammond, G., 2009. Transformation - An Assessment. Crosscutting Issues in International Transformation. Washington DC: National Defense University.

9. Kaplan, R., Norton, D., 2001. The strategy-focused organization. Harvard Bussines School Press.

10. Kruse, K., 2013. What is leadership? http://www.forbes.com/sites/kevinkruse/2013/04/09/ what-is-leadership/. 8. 9. 13.

11. Labbe, P., 2005. TTCP Guide for Understanding and Implementing Defense Experimentation, http://www.acq.osd.mil/ttcp/guidance/documents/ GUIDExBookFeb2006.pdf, 11. 4. 2012.

12. Laske, O., 2001. A learning-and-growth metric for strategy focused organizations. https:// balancedscorecard.org/Portals/0/PDF/Laske4.pdf, 25. 9. 2013.

13. Martin, A., in Ernst, C., 2005. Leadership, learning and human resource.

14. Management. Exploring leadership in times of paradox and Complexity Emerald Group Publishing Limited: Corporate Governance. 5-3, str. 82-94.

15. McCauley, C., in Van Velsor, E., The Center for Creative Leadership Handbook of Leadership Development, 2. izdaja, San Francisco, CA: Jossey-Bass/Wiley Publishers.

16. Mc Cauley, C. D., 2008. Interdependent Leadership in Organizations, Center for Creative leadership. Greensboro: North Carolina.

17. Nato MC, 2009. MC Policy for NATO Concept Development and Experimentation, Military Decision on MC 0583.

18. NATO SACT, 2005; Managing transformation, Directive 80-7.

19. O'Rourke, R., 2006. Defense Transformation: Background and Oversight Issues for Congress. CRS Report for Congress. Washington: Congressional Research Service. The Library of Congress.

20. Popovič, A., Coelho, P. S. \& Jaklič, J. 2009. The impact of business intelligence system maturity on information quality. Information Research, 14(4) paper 417.

21. SAZU in avtorji, 2008, Slovar slovenskega knjižnega jezika, 2008, Inštitut za slovenski jezik Frana Ramovša ZRC.

22. Poslovni slovar: http://www.businessdictionary.com/definition/leadership.html, 8. 9. 13.

23. Resolucija o splošnem dolgoročnem programu razvoja in opremljanja Slovenske vojske do leta 2025, Uradni list RS, št. 99/2010, z dne 7. 12. 2010, Ljubljana.

24. Roussel, J., 2008. Capability-Driven Operational Transformation: A new approach to large-scale change management. PRTM.

25. Sloan E., 2007. Military Transformation: Key Aspects and Canadian Approaches. Ottawa: Canadian Defense \& Foreign Affairs Institute.

26. Smith E., 2006. Complexity, networking, and effects-based approaches to operations. CCRP Publication Series, publications@dodccrp.org.

27. Šavc, P., Mikuž, I., 2011. Razvoj Slovenske vojske v drugem desetletju njenega obstoja. Ljubljana: Generalštab Slovenske vojske: Sodobni vojaški izzivi 13/št. 2, str. 61-81.

28. Šteiner, A., 2009. Čas je za transformacijo. Ljubljana: Generalštab Slovenske vojske: Sodobni vojaški izzivi 3/11, str. 119-123.

29. Šteiner, A., 2011. Transformacija - jo hočemo, jo zmoremo?, Ljubljana, Generalštab Slovenske vojske: Sodobni vojaški izzivi 13/št. 2, str. 43-61.

30. Teriff T., Osinga, F., Farell, T., 2010. A Transformation Gap? American Innovations and European Military Change. Stanford University Press. 